\title{
Theories of psychosis versus what it is like
}

In his interesting comments to my paper, Mohammed Abouelleil Rashed distinguishes between different senses in which one can try to render psychosis "intelligible". One might try to explain what the psychotic worldview looks like from the inside and what it is like to go through this kind of experience, or present an intelligible theory about psychosis. Philosophers of psychiatry have, of course, mostly been preoccupied with the latter project, and, according to Rashed, so am I, despite my stated intention to do the former.

To some extent, I believe this is fair criticism. All philosophers whose interests touch on phenomenology are likely prone to over-intellectualizing their experiences, and I might likewise be prone to intellectualize my psychotic experiences in a way that turn them into something psychotic non-philosophers might not altogether recognize. By this, I do not mean to say that my descriptions and explanations are not true to my experiences or memories thereof, but the fact that I am a philosopher might influence how I experience and remember things in the first place. If the social sciences and humanities are complicated by the fact that observing people changes the people one observes, this should be especially true when scholars observe themselves.

Nevertheless, I will push back against the critique: I do not believe that theorizing on the one hand and understanding what it was like for someone on the other, are projects as radically different as Rashed suggests.

In my paper, I argue against the claim that whereas we understand most people's actions in terms of beliefs, desires, and reasons, we must use a special kind of understanding - focused on what it is like to go through bizarre experiences and how they might affect speech and behaviour - to understand psychotic people. I point out that as a matter of fact, there is plenty of non-psychotic and perfectly commonplace behaviour that we understand in the latter way rather than the former, and there are psychotic beliefs and actions for which reasons can be given. We need a mix of these allegedly different types of understanding, whether the person we want to understand is psychotic or not. But explaining one's reasons for belief and action might in turn require some theorizing, depending on their basis.

I give examples, in my text, of causal explanations that provide no intelligibility in my sense - no insight into what it was like, nor the person's reasons as seen from their own point of view - like the hypothesis that delusional people have lost the ability to accurately assess probabilities. I also, occasionally, move into pure what-it-is-like-territory, like when I compare a threatening feeling of significance with foreshadowing in a horror movie. I don't have an 
explanation for this experience, it just is; the horror movie analogy is my best attempt at describing it in a way accessible to other people. But the discussion about bedrock loss very much straddles the line between trying to describe an experience and theorizing about it.

Although I lament in the paper that the experience of having your previously firm bedrock crumble beneath your (metaphorical and epistemological) feet is likely hard to picture for someone who has never been there, it is nevertheless something you experience and feel. But once it has been lost, lacking bedrock, you also lack any reason to trust other people's arguments about what is real or not. Here, we have a potential explanation for a general phenomenon psychotic and delusional people who seem impossible to argue with - but my having no reason to trust, e.g., my doctor when he claimed that I was imagining things, was also part of my experience at the time. I sat there thinking that his arguments were bad ones, because he kept presupposing what ought to be proved - that he was right and I was wrong, and that he was in touch with reality whereas I was not. Here, there is no neat separation between on the one hand reasons explanations and a theory couched in such terms, on the other hand what it was like to experience it first-hand.

If a refusal to theorize about psychosis includes a refusal to provide reasons explanations and bases for these reasons, I do not believe it is a fruitful strategy for madpeople striving for recognition. A refusal to engage in reasons explanations of psychotic beliefs and actions would entail accepting the idea that we cannot be understood the way other people can; rather, we require some odd, esoteric, special version of understanding. Purely causal explanations, not couched in terms of reasons, risk turning us into specimens for study, but giving up on reasons explanations risks turning us into non-agents, passive victims of bizarre experiences and thought patterns.

To quote Jeanette Kennett's comments to my paper: "In doing so her account highlights an important ground of respect for persons that is largely undiminished in psychosis. This is the striving to make sense of oneself and one's experience of the world that is fundamental to human agency." 